\title{
Ovarian Vein Thrombophlebitis: Case Report
}

\section{Sanchez AV*, RG Merino, Maria Teresa CG and Strikes RG}

Department of Internal Medicine, Carlos Haya Regional University Hospital, Malaga, Spain

\begin{abstract}
The ovarian vein thrombophlebitis (TVO) is a rare entity which it may occur during the immediate postpartum period and carries considerable morbidity. Its incidence is 0.15 to $0.18 \%$ at vaginal delivery, with a mortality rate of $18 /$ million pregnancies, being more common after cesarean (1-2\%). We present a patient with postpartum TVO, which in the present study hypercoagulable positive lupus anticoagulant, to our knowledge there are only two cases reported in the medical literature, this being first diagnosed in the immediate postpartum. It also presents culture positive lochia, which is rare in cases described previously, and inferior vena cava thrombosis, one of the possible complications of TVO.
\end{abstract}

Keywords: Ovarian vein thrombophlebitis; Antiphospholipid syndrome; Thrombophlebitis

\section{Introduction}

The ovarian vein thrombophlebitis (TVO) is a rare entity, first described by Austin et al. [1], which it may occur during the immediate postpartum period and carries considerable morbidity. Its incidence is $0.15 \%$ to $0.18 \%$ at vaginal delivery [2], with a mortality rate of $18 /$ million pregnancies, being more common after cesarean (1-2\%) [3].

We present a patient with postpartum TVO, which in the present study hypercoagulable positive lupus anticoagulant, to our knowledge there are only two cases reported in the medical literature [4], this being first diagnosed in the immediate postpartum. It also presents culture positive lochia, which is rare in cases described previously, and inferior vena cava thrombosis, one of the possible complications of TVO.

\section{Case Report}

A female of 24 years Surgery for vesicoureteral reflux in children, Primípara. He presented gestational diabetes mellitus with good metabolic control. Planned caesarean section for twin presentation facility. The $5^{\text {th }}$ day post-intervention consultation begins with spiking fevers in daily needle to 40 with abdominal tenderness. And extracted blood cultures were negative urine culture, culture being positive Enterococcus faecalis loquios to. A month before the caesarean in vaginal discharge Streptococcus agalactiae was detected. In the analytical highlights anemia ( $\mathrm{Hb} 9.2 \mathrm{mg} / \mathrm{dL}$ and leukocytosis 12,320 with $89 \%$ neutrophils). On examination detected wound seroma, no other findings, so empirical treatment is initiated with amoxicillinclavulanate. The $4^{\text {th }}$ day of antibiotic treatment, persistent fever, and treatment is modified gentamicin, clindamycin and ampicillin.

$48 \mathrm{~h}$ unanswered abdominopelvic computed tomography is requested, which $2 \times 12 \mathrm{~cm}$ Tubular structure described in the lower portion of the blind, attenuation increased fat-free liquid adjoining periappendiceal. The structure compressed into the middle of the right ureter third producing a discrete degree of pyelocalyceal ectasia (Figure 1). Given the poor prognosis of the patient performing exploratory laparotomy was decided with the following findings: normal appendix, performing prophylactic appendectomy and retroperitoneal tubular structure woody $3 \times 12 \mathrm{~cm}$, originating in right infundibulopelvic parallel vein, however, IVC thrombosis suggestive of ovarian vessels rights to its mouth in inferior vena cava. Closing and expectant attitude is decided. It starts anticoagulation with low molecular weight heparin (LMWH) prophylactic doses. Absolute contraindication to anticoagulation lower cavography where filling defect right side, below renal veins, which corresponds to the arrival of the thrombosed vein is checked and transient Günther Tulip filter is implanted between said filling defect and subsequently performed inserting renal veins, checking correct positioning in subsequent control (Figure 2). Chest $\mathrm{CT}$ angiography in which discarded filling defect in pulmonary vascular tree is performed. It trascurrida one week laparotomy starts full dose LMWH. The filter is removed after 21 days without complications and treatment is initiated with warfarin. Test results thrombophilia are: prothrombin gene mutation, factor $\mathrm{V}$ Leiden, protein $\mathrm{C}$ and $S$, antithrombin III negative. Anicuerpos normal IgG and IgM antcardiolipina. 9 AntiB2Glicoproteína IgM, IgG AntiB2GP 35 lupus anticoagulant positive. A $2^{\text {nd }}$ determination is performed 8 weeks later: 33 AntiB2GP IgM, IgG AntiB2GP 26 1/40 speckled pattern antinuclear antibodies, ENA negative, negative neutrophil cytoplasmic antibodies,

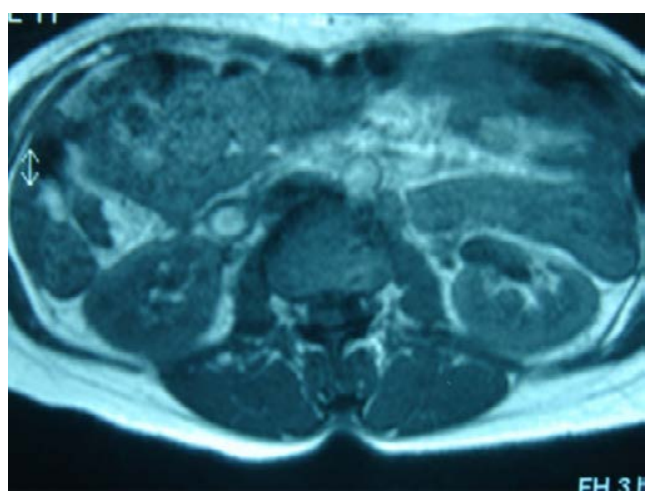

Figure 1: The structure of pyelocalyceal ectasia

*Corresponding author: Sanchez AV, Department of Internal Medicine Service, Carlos Haya Regional University Hospital, Malaga, Spain, Tel: +34951290000; E-mail: auroravillalobos@gmail.com

Received July 30, 2015; Accepted December 03, 2015; Published December 12,2015

Citation: Sanchez AV, Merino RG, Maria Teresa CG, Strikes RG (2015) Ovarian Vein Thrombophlebitis: Case Report. J Vasc Med Surg 3: 237. doi:10.4172/23296925.1000237

Copyright: (c) 2015 Sanchez AV, et al. This is an open-access article distributed under the terms of the Creative Commons Attribution License, which permits unrestricted use, distribution, and reproduction in any medium, provided the original author and source are credited. 


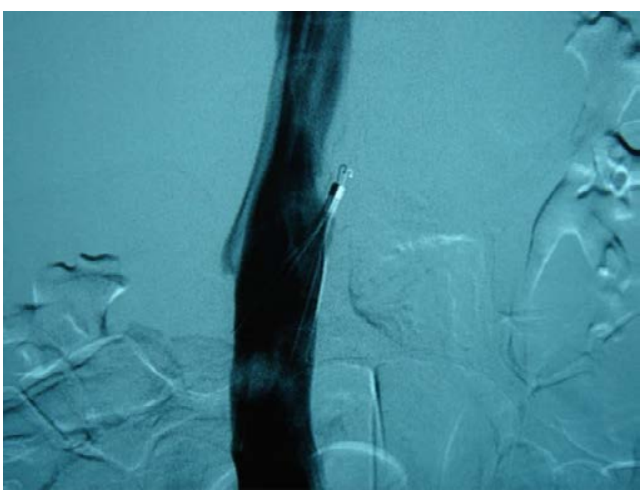

Figure 2: Transient günther tulip filter.

lupus anticoagulant positive. Three months after the episode described echo Doppler right ovarian vein is performed with normal results. Since the diagnosis of primary antiphospholipid syndrome (APS) with TVO indefinite anticoagulation is decided.

\section{Discussion}

Postpartum ovarian thrombophlebitis presents clinically as fever, abdominal pain together with feeling flank mass. It can occur in the postpartum period or other pelvic procedures [5]. 90\% of cases occur in the first 10 postpartum days and affects the right ovarian vein, due to its greater length, greater valvular incompetence, uterine dextrotorsión during pregnancy and presence of expansion and antegrade flow postpartum thereof [6].

The pathogenesis of TVO is explained by the triad of Virchow and the unique conditions of hemostasis occurring during the postpartum period (decreased protein S, increased factors II, VII, IX, X, increase adherence, Platelets, decreased activity fibrinolytic) and trauma that occurs during labor that facilitates intrauterine infection, inflammation and leukocyte infiltration [7].

Although intrauterine infection is present or suspected in the onset of symptoms, to crops extracted persistent fever are negative in most cases [8], smaller percentages describing culture positive cases $35 \%$ [9]. This low profitability may be due in part to the introduction of empirical antibiotic treatment prior to diagnosis. In the case presented loquios culture was positive for Enterococcus faecalis.

As for prothrombotic predisposition, there are numerous acquired risk factors described in relation to TVO. In a retrospective study includes 22 patients with TVO, the primary hypercoagulable state was present in half of the patients with TVO puerperal highlighting heterozygosity for factor $\mathrm{V}$ Leiden, protein $\mathrm{S}$ deficiency, or homozygous for mutation in methylenetetrahydrofolate reductase [10].

The SAF is a well known thrombosis including unusual locations [11], although to date there are only two cases reported in the literature TVO and SAF [4], including a recent European cohort of 1000 patients with APS [12] causes. 2 have also been described in cases of a series TVO autopsy in patients with catastrophic syndrome [13].

Despite being an atypical localization of thrombosis, recent studies like rethrombosis risk it is found that DVT affects lower limbs, with no significant difference in survival five years. Poor survival rate is explained by cases associated with malignancy. As for possible complications in this series comprising 114 patients, only 1 presented vena cava extension [14], as in the case presented. He, although rare, pulmonary thromboembolism is a complication that must be present in body [15].

\section{Conclusion}

Due to the low incidence of TVO and its considerable morbidity and mortality, it is necessary a high clinical suspicion in cases with symptoms compatible to establish diagnosis, early treatment and establish comprehensive medical surveillance. We must examine this possibility more febrile postpartum abdominal pain and surgical procedures, infection or cancer in the pelvic area. The diagnostic technique of choice is MRI or abdominal computed tomography. The treatment of choice is based on LMWH with broad-spectrum antibiotics. Because described his recent association with acquired and inherited bleeding disorders should be performed thrombophilia testing and microbiological culture despite its apparent low profitability.

\section{References}

1. Austin OG (1956) Massive thrombophlebitis of the ovarian veins; a case report. Am J Obstet Gynecol 72: 428-429.

2. Dessole S, Capobianco G, Arru A, Demurtas P, Ambrosini G (2003) Postpartum ovarian vein thrombosis: an unpredictable event: two case reports and review of the literature. Arch Gynecol Obstet 267: 242-246.

3. Cunningham FC, MacDonald PC, Leveno KJ (1993) Puerperal infection.

4. André M, Delèvaux I, Amoura Z, Corbi P, Courthaliac C, et al. (2004) Ovarian vein thrombosis in the antiphospholipid syndrome. Arthritis Rheum 50: 183186.

5. Duff P, Gibbs RS (1983) Pelvic vein thrombophlebitis: Diagnostic dilemma and therapeutic challenge. Obstet Gynecol Surv 38: 365-373.

6. Witlin AG, Mercer BM, Sibai BM (1996) Septic pelvic thrombophlebitis or refractory postpartum fever of undetermined etiology. J Matern Fetal Med 5 355-358.

7. Dunnihoo DR, Gallaspy JW, Wise RB, Otterson WN (1991) Postpartum ovarian vein thrombophlebitis: a review. Obstet Gynecol Surv 46: 415-427.

8. Kominiarek MA, Hibbard JU (2006) Postpartum ovarian vein thrombosis: An update. Obstet Gynecol Surv 61: 337-342.

9. Collins CG (1970) Suppurative pelvic thrombophlebitis: A study of 202 cases in which diseases was treated by ligation of the vena cava and ovarian vein. Am J Obstet Gynecol 108: 681-687.

10. Salomon O, Apter S, Shaham D, Hiller N, Bar-Ziv J, et al. (1999) Risk factors associated with postpartum ovarian vein thrombosis. Thromb Haemost 82 1015-1019.

11. Kaushik S, Federle MP, Schur PH, Krishnan M, Silverman SG, et al. (2001) Abdominal thrombotic and ischemic manifestations of the antiphospholipid antibody syndrome: CT findings in 42 patients. Radiology 218: 768-771.

12. Cervera R, Piette JC, Font J, Khamasha MA, Shoenfeld $Y$, et al. (2002) Antiphosphoslipid syndrome: clinical and immunological manifestations and patterns of disease expressions in the cohort of 1000 patients. Arthritis Rheum 46:1019-1027.

13. Soltész P, Szekanecz Z, Végh J, Lakos G, Tóth L, et al. (2000) Catastrophic antiphospholipid syndrome in cancer. Haematologia (Budap) 30: 303-311.

14. Wysokinska EM, Hodge D, McBane RD (2006) Ovarian vein thrombosis: incidence of recurrent venous thromboembolism and survival. Thromb Haemost 96: 126-131.

15. Verde F, Johnson PT (2012) One Not to Miss: Ovarian Vein Thrombosis Causing Pulmonary Embolism with Literature Review. J Radiol Case Rep 6 : 23-28 